\title{
PSYCHOLOGICAL DISTRESS AMONG CANCER PATIENTS ON CHEMOTHERAPY
}

\author{
Nor Zuraida Z, Ng CG \\ Department of Psychological Medicine, University of Malaya, Kuala Lumpur, Malaysia.
}

\begin{abstract}
:
Distress has become a major issue in cancer population. Patients may suffer from either physical, psychological distress or both. Cancer patients who are undergoing chemotherapy are more likely to experience psychological distress. This could be due to the negative effects of chemotherapy agents, the uncertainty of post-treatment, and the occurrence of psychosocial problems. As a result, the patient may experience a normal reaction such as sadness or may develop common psychiatric disorders such as depression and anxiety. (JUMMEC 2010; 13(1): 12-18)
\end{abstract}

KEYWORDS: psychological distress, anxiety, depression, cancer, chemotherapy

\section{Introduction}

Psychological distress is the uncomfortable emotional response to a perceived harmful event such as upon receiving a diagnosis of cancer. "Distress" is the most commonly used term in oncology literature to describe the whole range of negative psychological responses experienced by the cancer patients $(1,2)$. It has been defined as "a multifactorial unpleasant emotional experience of a psychological (cognitive, behavioral, emotional), social, and/or spiritual nature that may interfere with the ability to cope effectively with cancer, its physical symptoms, and its treatment" $(3,4)$.

A lot of research has been done in determining psychological distress in cancer patients (5-7). The prevalence of long-term psychological distress in cancer patients ranges from $20 \%$ to $60 \%(8,9)$. It is due to the inconsistencies of study methods such as the assessment tools used and study populations included. Among the various types of psychological responses, anxiety and depression received most attention in the studies of cancer patients (10). Anticipatory anxiety and post traumatic stress disorder are the two types of anxiety known to be related to the initiation and consequence of cancer treatment (10-13). Depression encompasses a spectrum that ranges from normal sadness to major depressive disorder. It is an understandable reaction to the fear of cancer and closely linked with the somatic complaints and its treatment (10).
Chemotherapy is the most frequently used treatment modality in cancer patients. It is well-known in causing a wide range of side effects such as nausea and vomiting, tiredness or fatigue, sore mouth, reduced fertility, peripheral neuropathy, and skin problems $(14,15)$. It leads to high level of distress and impacts on the quality of life in cancer patients receiving chemotherapy. As people live longer after treatment for cancer, attention turned to the survivor's quality of life and the distress that they may experience (10). As a result, it is important to monitor the psychological well-being in this group of patients as part of the routine care (4). It can be achieved by increasing the awareness and proficiency of oncology health care provider in recognizing and instituting optimal treatment for psychological distress in cancer patients.

Psychological distress in cancer patients who are on treatment, particularly chemotherapy, need to be determined and understood (16). This is the primary focus of this article.
Correspondence:
Ng Chong Guan
Department of Psychological Medicine
University of Malaya Medical Centre
50603 Kuala Lumpur, Malaysia
Email: chong_guan@hotmail.com 


\section{Factors Related to Psychological Distress in Cancer Patients}

Before we discuss the psychological issues that arise in patients receiving chemotherapy, we need to understand the factors related to psychological distress in these patients. It was described by Andrykowski et al that psychological distress is due to the imbalance between two variables (17). The first variable is the "stress and burden" perceived by the cancer patients. It disrupts the psychological health of a patient. The second variable is the "resources" available to cope with the stress and maintain the psychological equilibrium (17). Various patient and disease characteristics that were found to be potential risk factors for psychological distress increase the burden experienced by the cancer patients. For example, the number of stressful life events, previous history of depression and premorbid psychiatric status (18).

Similarly, those factors that reduce the resources to cope with stress will result in higher psychological distress in cancer patients. Marital status, social class and financial status were predictors of high psychological distress which reduce the coping resources of a cancer patient $(19,20)$. A study on patients who underwent chemotherapy in Malaysia suggested that the prevalence of psychological distress determined by a "distress thermometer" was 51\%. Distress was significantly associated with psychosocial problems (16). Another interesting example is the effects of age on emotional distress after a mastectomy. The results revealed that younger women apparently have resources that protect them against depression, although they are more likely to fear the recurrence of the disease and they worry more about disfigurement resulting from surgery. It conflicted with other studies that suggest marriage is protective against distress during stressful life events (21).

\section{Normal Response to the Stress of Cancer}

Rasmussen and Elverdam described cancer as a "symbol of disruption of life and time, and the harmony of ordinary life disappears" (22). The psychological response toward a life threatening disease such as cancer varies between individuals. It begins with shock and disbelief, followed by a mix of negative psychological responses and somatic complaints. Most people will recover from the emotional turmoil and recollect the psychological equilibrium $(2,17)$. The period of recovery relied on the support from family, friends, personal coping skill and physician for those who opt to have a treatment plan that offer hope $(2,23)$.

Some individuals do not fully recover and continue to have a low level of psychological distress which persists for weeks or months. For some, the condition deteriorates and leads to marked physical, psychological and social impairment and subsequently requires psychiatric treatment (17). An early study found that $53 \%$ of these patients were adjusting normally to stress; the remaining $47 \%$ had apparently clinically psychiatric disorders. Of the $47 \%$ with psychiatric disorders, $68 \%$ had adjustment disorders with depressed or anxious mood, $13 \%$ had a major depression, and $4 \%$ had a preexisting anxiety disorder (21).

\section{Anxiety}

Anxiety is well documented in patients with the diagnosis of cancer and the initiation of treatment (10-13). Patients are confronted with the worry of death at the time of diagnosis. It leads to a substantial level of anxiety. Gradually, it is followed by the fear of recurrence, disrupted belief of life expectancy and loss of focus in living $(22,24-28)$. The initiation of treatment such as chemotherapy add further emotional burden to the patients, which attributed to the potential adverse effects. There are two specific anxiety disorders, namely anticipatory anxiety and posttraumatic stress disorder (PTSD), which are believed to be closely linked with the treatment of cancer that significantly affect the patient's functioning, compliance and quality of life $(10-13,22,24,29)$.

Nausea and vomiting are common side effects of chemotherapy. It leads to several physical complaints such as loss of appetite and weight. The subsequent development of psychological nausea and vomiting which is known as anticipatory nausea and vomiting (ANV) is widely studied (10-13, 30-37). The common explanation for ANV is conceptualized as a learning process (38). The stimulation during drug administration followed by the drug related side effects triggers a conditioning process. As a result, 
nausea and vomit are experienced during the next cycle of treatment even before drug administration. Autonomic reactivity and conditionability of an individual play distinct roles in determining the risk of developing ANV during chemotherapy (36). Patients with trait anxiety and post-treatment nervousness have a higher risk of ANV (35). Other predicting factors for ANV found in previous studies are younger age, history of susceptibility to motion sickness and history of side effects from previous chemotherapy (37). Understanding of this concept is important for health care providers who provide screening and treatment of ANV in cancer patients who are receiving chemotherapy.

Another specific type of anxiety that received much attention in the study of cancer patients is PTSD. The reported prevalence ranges from $18-80 \%$ depending on the time period of study and severity of the disorder (39-41). A study that used stringent diagnosis criteria for cancer related PTSD in breast cancer patients after completion of treatment shown that the prevalence rate was as low as 3\% (42). However, before considering the biological explanation for PTSD in cancer patients, we need to accept that the diagnosis of cancer or treatment resembles a typical type of event or trauma that gives rise to PTSD (24). An abrupt disclosure of the diagnosis of cancer and the administration of treatment closely represent a traumatic event comparable with the disease itself which is an ongoing stress for an individual.

Many studies, which look into the underlying neuroendocrinologic processes that lead to PTSD in cancer patients has been conducted (43-45). Previous studies found that there were corticotrophin releasing factor (CRF) hypersecretion with relatively low level of adrenocorticotropic hormone (ACTH) and cortisol in cancer related PTSD. Negative feedback inhibition was hypothesized by Yehuda to explain this hypothalamic-pituitary-adrenal (HPA) alteration in PTSD (43). Another interesting finding was the lower amygdala volume in PTSD patients (44-45). These biological changes were suggested to trigger the emotional response and persistent of anxiousness in patients with PTSD. The patients re-experience and have persistent intrusive thoughts or memories of the traumatic events. The knowledge regarding the causative process of PTSD is helpful in the development of treatment for this group of patients.

\section{Depression}

Cancer is recognized as a significant psychosocial stressor and predisposes to depression. Many researchers have assessed depression in cancer patients in the past decades and the reported prevalence varies significantly because of the varying diagnosis criteria, measurement or rating scales used and differences in the study populations (21, 46-49). Based on the study by Derogatis et al, $6.1 \%$ of the cancer patients met the criteria for major depressive disorder (21). According to the review article by Mc Daniel et al, the figure was higher for cancer inpatients which is $8 \%$ and 15 to $36 \%$ for all depressive disorders (46). The prevalence also determined by the site of cancer. It is highly prevalent in oropharyngeal and pancreatic cancer but less common in gynaecological and lymphoid cancer (50).

There was a long standing debate on the diagnosis of depression in cancer patients (21). It is due to the overlapping of somatic symptoms in depression with the physiological symptoms in cancer and its treatment such as fatigue, loss of appetite and weight, sleep difficulties, poor memories and concentration. This group of symptoms was referred to as "sickness syndrome" by the recent researchers and believed to be caused by the pathophysiological process of the cancer and its treatment $(51,52)$. It involved the activation of immune system and proinflammatory cytokine system and lead to depression in cancer patients (51-53).

Increased level of stress hormone, cortisol and hyperactivity of the stress system were another hypothesis suggested as the pathophysiological process of depression $(24,54)$. It is associated with the progress of cancer and affects the treatment outcome by lowering the defense mechanisms (55). It is recognized that the treatment of depression is beneficial regardless of the etiology of the "sickness syndrome" (56).

In addition, arousal (alertness vs boredom) and valence (positive vs negative) are two dimension of emotion that could predict fatigue and depression in 
patients undergoing chemotherapy (57-60). This was the pathophysiologic explanation that depression is associated with stress response system.

Depressed patients were more likely to develop anxiety, fatigue and insomnia. It leads to non compliance, refusal of treatment, poor quality of life and shortened life expectancy $(61,62)$. A study shown that only $51.3 \%$ of breast cancer patients with concomitant depression accepted and received the proposed chemotherapy as comparing to the $92.2 \%$ of the control group (63).

It is often reported that the recognition of psychiatric need in cancer patients is poor among health care providers. There were fewer than half of the patients with cancer related depression symptoms were offered treatment (64-67). Health care providers do not prioritize mental health issues and lack of effective communication with patients is the two main reasons of under-recognition and under-treatment of depression in cancer patients $(64,65)$. Depression is a progressive condition and it responses better to treatment at the earliest phase because of the nature of the alteration in the neurological process $(68,69)$. Oncology health care providers should be more proficient in psychosocial assessment and able to detect subtle signs, monitor risk factors and reduce depression in cancer patients. Adequate management of depression required the consistent and informed involvement of health care providers and caregivers (69). This will improve the quality of care and reduce the psychological distress in cancer patients.

\section{Conclusions}

The significant experience of psychological distress among cancer patients undergoing chemotherapy should not be left unrecognized and untreated. Factors that concern the patients should be addressed accordingly, and in doing so, there may be a need for a multidisciplinary approach. Therefore, the role of the mental health team in managing cancer patients is very important.

\section{References}

1. Ridner SH. Psychological distress: concept analysis. J Adv Nurs 2004; 45(5): 536-545.
2. Ann MB, John LS, Jamie HVR. Principles and Practice of Palliative Care and Supportive Oncology. 3rd ed. Philadelphia: Lippincott Williams \& Wilkins; 2007: 445-466.

3. Wilkes G. Depression. Cancer Source RN. 2003. http://www.cancersourcern.com/search/ getcontent.cfm?DiseaselD $=1$ \&Contentid $=16193$. Accessed 20 Sept 2009.

4. Distress management clinical practice guidelines in oncology. J Natl Compr Canc Netw 2003; 1(3): 344-374.

5. Grassi L, Travado L, Moncayo FL, Sabato S, Rossi E, SEPOS Group. Psychosocial morbidity and its correlates in cancer patients of the Mediterranean area: findings from the Southern European PsychoOncology Study. J Affect Disord 2004; 83: 243-248.

6. Jacobsen $\mathrm{PB}$, Donovan KA, Trask PC, Fleishman SB, Zabora J, Baker F, Holland JC. Screening for psychological distress in ambulatory cancer patients. Cancer 2005; 103(7): 1494-1502.

7. Gil F, Grassi L, Travado L, Tomamichel M, Gonzalez JR, Southern European Psycho-Oncology Study Group. Use of distress thermometers to measure psychosocial morbidity among southern European cancer patients. Support Care Cancer 2005; 13: 600606.

8. Breitbart WS. Identifying patients at risk for, 0 and treatment of major psychiatric complications of cancer. Support Care Cancer 1995; 3: 45-60.

9. Rieker PP, Fitzgerald EM, Kalish LA, Richie JP, Lederman GS, Eabril SD, Garnick MB. Psychological factors, curative therapies and behavioral outcomes: a comparison of testis cancer survivors and a control group of healthy men. Cancer 1989; 64: 2399-2407.

10. Vachon M. Psychosocial distress and coping after cancer treatment. AJN 2006; 106 (3) supp; 26-31.

11. Desaive $P$, Ronson A. Stress spectrum disorders in oncology. Curr Opin Oncol 2008; 20: 378-385.

12. Olafsdottir, Sjödèn PO, Westling B. Prevalence and prediction of chemotherapy-related anxiety, nausea and vomiting in cancer patients. Behav Res Ther 1986; 24: 59-66. 
13. Watson M, Mc Carron J, Lam M. Anticipatory nausea and emesis, and psychological morbidity: assessment of prevalence among out-patients on mild to moderate chemotherapy regimes. $\mathrm{Br} J$ Cancer 1992; 66: 862-866.

14. Del Mastro L, Costantini M, Morasso G, Bonci F, Bergaalio M, Banducci S, Viterbon P, Cente $P$, Rosso R, Venrarini M. Impact of two different dose-intensity chemotherapy regimes on psychological distress in early breast cancer patients. Eur J Cancer 2002; 38: 359-366.

15. Priestman T. Coping with Chemotherapy. London: Sheldon Press; 2005; 32-41.

16. Nor Z, Hui K, Hang T, Bustam A. Prevalence of distress in cancer patients undergoing chemotherapy. AsiaPacific J Clin Oncol 2007;3: 219-223.

17. Andrykowski MA, Lykins E, Floyd A. Psychological health in cancer survivors. Semin Oncol Nurs 2008; 24(3): 193-201.

18. Followfield FJ, Baum M. Psychosocial problems associated with the diagnosis and initial treatment of breast cancer. In: Bland KI, Copeland EM III, editors. The breast: comprehensive management of benign and malignant diseases. Philadelphia: WB Saunders: 1991: 1081-1092.

19. Dean C. Psychiatric morbidity following mastectomy: preoperative predictors and types of illness. J Psychosom Res 1987; 31: 385-392.

20. Mishra S, Bhatnagar S, Philip FA, Singhal V, Rana SPS, Upadhyay SP, Chauhan G. Psychosocial concerns in patients with advanced cancer: anobservational study at regional cancer centre, India. Am J Hosp Palliat Care 2010; 18: 1-4.

21. Derogatis LR, Morrow GR Fetting J, Penman D, Piasetsky J, Schmale AM, Henrichs M, Carnicke CL Jr. The prevalence of psychiatric disorders among cancer patients. JAMA 1983; 249(6): 751-757.

22. Rasmussen DM, Elverdam B. Cancer survivors' experience of time-time disruption and time appropriation. J Adv Nurs 2007; 57(6): 614-622.

23. Burgess C, Morris T, Pettingale KW. Psychological response to cancer diagnosis II. Evidence for coping styles (coping styles and cancer diagnosis). J Psychosom Res 1988; 32(3): 263272.

24. Ronson A. Psychiatric disorders in oncology: recent therapeutic advances and new conceptual frameworks. Curr Opin Oncol 2004; 16: 318-323.

25. Vachon MLS, Lancee WS, Ghadirian P, Adair W. Final report on the needs of persons living with cancer in Manitoba. Toronto: Canadian Cancer Society; 1990.

26. Vachon MLS, Conway B, Lancee WS. Final report on the needs of persons living with cancer in Prince Edward Island. Toronto: Canadian Cancer Society; 1989.

27. Vachon MLS, Lancee WS, Ghadirian P, Adair W. Final report on the needs of persons living with cancer in Quebec. Toronto: Canadian Cancer Society; 1991.

28. Sanson-Fisher R, Gigis A, Boyes A, Bonerski B, Burton $L$, Cook $P$. The unmet supportive care needs of patients with cancer. Supportive Care Review Group. Cancer 2000; 88(1): 226-237.

29. Wise MG, Rundell JR. Psychiatric in the medically ill. The American Psychiatric Publishing Textbook of Consultation-Liaison Psychiatry. 2nd ed. Washington: American Psychiatric Publishing, Inc; 2002: 657-678.

30. Andrykowski MA, Redd WH, Hatfield AK. Development of anticipatory nausea: a prospective analysis. J Consult Clin Psychol 1985; 53: 447-454.

31. Andryskowski MA. Defining anticipatory nausea and vomiting: differences among cancer chemotherapy patients who report pretreatment nausea. J Behav Med 1988; 11: 59-69.

32. Nerenz DR, Leventhal $H$, Love RR. Factors contributing to emotional distress during cancer chemotherapy. Cancer 1982; 50: 1020-1027.

33. Altmaier EM, Ross WE, Moore K. A pilot investigation of the psychological function of patients with anticipatory vomiting. Cancer1982; 49: 201-204.

34. Ingle RJ, Burish TG, Wallston KA. Conditionability of cancer chemotherapy patients. Onco Nurs Forum 1984; 11: 97-102. 
35. Jocobsen PB, Bovbjerg DH, Redd WH. Anticipatory anxiety in women receiving chemotherapy for breast cancer. Health Psychol 1993; 12(6): 469-475.

36. Kvale G, Hugdahl K, Asbjornsen A, Rosengren $B$, Lote K, Nordby $\mathrm{H}$. Anticipatory nausea and vomiting in cancer patients. J Consult Clin Psychol $1991 ; 59(6) 894-898$.

37. Morrow GR. Clinical characteristics associated with the development of anticipatory nausea and vomiting in cancer patients undergoing chemotherapy treatment. J Clin Oncol 1984; 2: 1170-1176.

38. Ellis HC, Bennett TC, Daniel TC, Rickett EJ: Psychology of learning and memory. Monterey, CA: Brooks Cole Publishing; 1979: 33-34.

39. Kwekkeboom KL, Seng JS. Recognizing and responding to post-traumatic stress disorder in people with cancer. Oncol Nurs Forum 2001; 29(4): 643-650.

40. Miovic M, Block S. Psychiatric disorders in advanced cacner. Cancer2007; 110: 1665-1676.

41. Smith MY, Redd WH, Peyser C, Vogl D. Posttraumatic stress disorder in cancer: a review. Psychooncology 1999; 8(6): 521-537.

42. Hakamata $Y$, Matsuoka $Y$, Inagaki $M$, Nagamine M, Hara E, Imoto S, Murakami K, Kim Y, Uchitomi $Y$. Structure of orbitofrontal cortex and its longitudinal course in cancer-related posttraumatic stress disorder. Neurosci Res 2007 ;59(4): 383-9

43. Yehuda R. Hypothalamic-pituitary-adrenal alterations in PTSD: are they relevant to understanding cortisol alterations in cancer? Brain Behav Immun 2003; 17 Suppl 1: S73-83.

44. Bremner JD. Neuroimaging studies in posttraumatic stress disorder. Curr Psychiatry Rep 2002; 4(4): 254-263.

45. Matsuoka Y, Yamawaki S, Inagaki M, Akechi T, Uchitomi Y. A volumetric study of amygdala in cancer survivors with intrusive recollections. Biol Psychiatry 2003; 54(7): 736-743.
46. McDaniel JS, Musselman DL. Depression in patients with cancer: diagnosis, biology, and treatment. Arch Gen Psychiat 1995; 52(2): 89-99.

47. Kathol RG, Mutgi A, Williams J, et al. Diagnosis of major depression in cancer patients according to four sets of criteria. Am J Psychiat 1990; 147: 1021-1024.

48. Massie MJ, Holland JC. Depression and the cancer patient. J Clin Psychiat 1990; 51: 12-19.

49. Sellick SM, Crooks DL. Depression and cancer: an appraisal of the literature for prevalence, detection, and practice guideline development for psychological intervention. Psychooncology; 8: 315-333.

50. Noyes SR, Holt CS, Massie MJ. Anxiety Disorders. In: JC Holland (ed). Psycho-Oncology. NY: Oxford University Press; 1998; 548-563.

51. Raison $\mathrm{CL}$, Miller $\mathrm{AH}$. Depression in cancer: new developments regarding diagnosis and treatment. Biol Psychiatry 2003; 54: 283-294.

52. Kent S, Bluthe Rm, Kelley KW, Dantzer R. Sickness behaviour as a new target for drug development. Trends Pharmacol Sci 1992; 13: 24-28.

53. Dentzer R. Cytokine-induced sickness behaviour: where do we stand? Brain Behav Immun 2001; 15: 7-24.

54. Spiegel D, Giese-Davis J. Depression and cancer: mechanisms and disease progression. Biol Psychiatry 2003; 54: 269-282.

55. Miranda $\mathrm{CR}$, de Resende CN, Melo CF, Costa Al Jr, Friedman $H$. Depression before and after uterine cervix and breast cancer neoadjuvant chemotherapy. Int J Gynecol Cancer 2002; 12:773-776.

56. Yirmiya $R$, Weidenfeld J, Pollak $Y$, Morag $M$, Morag A, Avitsur R, Barak O, Reichenberg A, Cohen E, Shavit $Y$ and Ovadia H. Cytokines, "Depression Due to A General Medical Condition," and Antidepressant Drugs. Adv Exp Med Biol 1999; 461: 283-316.

57. Kim YM, HickokJT, Morrow G. Fatigue and depression in cancer patients undergoing chemotherapy: an 
emotion approach. J Pain Symptom Manage 2006; 32(4): 311-321.

58. Russell JA. A circumplex model of affect. J Pers Soc Psychol 1980; 39: 1161-1178.

59. Thayer RE. The biopsychology of mood and arousal. NY: Oxford University Press; 1989.

60. Watson D, Tellegen A. Toward a consensual structure of mood. Psychol Bull 1985; 98: 219-235.

61. Lenz ER, Pugh LC, Milligan R, Gift A, Suppe F. The middle-range theory of unpleasant symptoms. An update. Adv Nur Sci 1997; 19(3): 14-27.

62. Redeker NS, Leu EL, Ruggiero J. Insomnia, fatigue, anxiety, depression and quality of life of cancer patients undergoing chemotherapy. Sch Inq Nurs Pract 2000; 14: 275-290.

63. Marco C, Mario M, Giullia P, Chris R, Anne B, Aron G. Depression and degree of acceptance of adjuvant cytotoxic drugs. Lancet 2000; 356(9238): 1326-137l.

64. Kadan-Lottick NS, Vanderwerker LC, Block SD et al. Psychiatric Disorders and Mental Helath Service
Use in Patients with Advanced Cancer. A Report from the Coping with Cancer Study. Cancer2005; 104: 2872-2881.

65. Maguire $P$, Tait $A$, Brooke $M$ et al. effect of counseling on the psychiatric morbidity associated with mastectomy. Br Med J 1980; 281: 1454-1456.

66. Passik SD, Dugan W, McDonald MV et al. Oncologists' recognition of depression in their patients with cancer. J Clin Oncol 1998; 16(4): 15941600.

67. McDonald MV, Passik SD, Dugan W et al. Nurses' recognition of depression in their patients with cancer. Oncol Nurs Forum 1999; 26(3): 592-599.

68. Lovejoy NC, Tabor D, Matteis M, Lillis P. Cancerrelated depression: Part I-neurologic alterations and cognitive-behavioral therapy. Oncol Nurs Forum 2000; 27(4): 667-678.

69. Lovejoy NC, Tabor D, Deloney P. Cancer-related depression: Part II-neurologic alterations and evolving approaches to psychopharmacology. Oncol Nurs Forum 2000;27(5):795-808. 